\title{
Correction to: Resveratrol attenuates norepinephrine-induced ovarian cancer invasiveness through downregulating hTERT expression
}

\author{
Seung Hwa Kim ${ }^{1} \cdot K_{y u n g} \mathrm{Hwa}_{\mathrm{Cho}}{ }^{1} \cdot$ Yu Na Kim${ }^{1} \cdot$ Bo Young Jeong $^{1}$ \\ Chang Gyo Park ${ }^{1} \cdot$ Gang Min Hur ${ }^{2}$ Hoi Young Lee ${ }^{1}$
}

Published online: 31 August 2018

(C) The Pharmaceutical Society of Korea 2018

\section{Correction to: Arch. Pharm. Res. (2016) 39:240-248 https://doi.org/10.1007/s12272-015-0666-8}

Unfortunately, there are some errors in Fig. 1b and Fig. 3a of the article.

In Fig. 1b, invasion images of REV and REV + NE are inadvertently duplicated during final figure assembly.
In Fig. 3a, the $\beta$-actin image is mistakenly duplicated with that in Fig. 3d.

The corrected Figs. 1 and 3 are shown in this erratum.

The authors apologize for these errors and any confusion it may have caused.

The original article can be found online at https:// doi.org/10.1007/s12272-015-0666-8.

Gang Min Hur gmhur@cnu.ac.kr

$\triangle$ Hoi Young Lee hoi@konyang.ac.kr

1 Department of Pharmacology, College of Medicine, Konyang University, 6 Munhwa-dong, Jung-gu, Daejeon 301-747, Republic of Korea

2 Department of Pharmacology, Daejeon Regional Cancer Center, College of Medicine, Chungnam National University, 821 Medical Science Bldg., 681 Gasuwon-dong, Seo-gu, Daejeon 302-718, Republic of Korea 

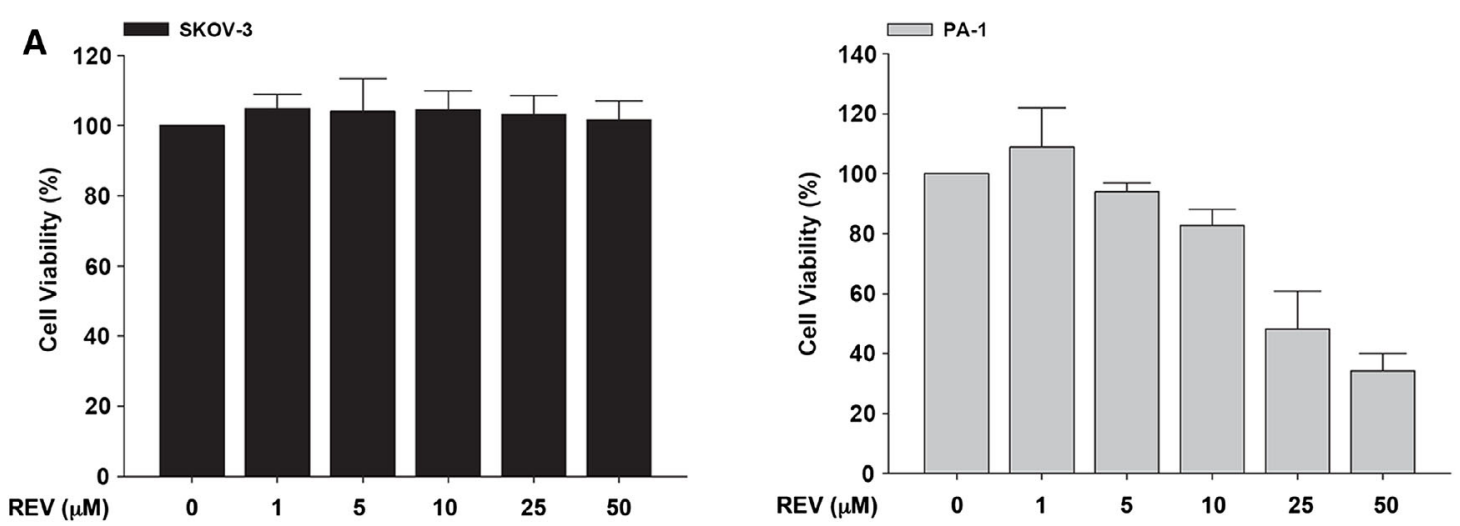

B
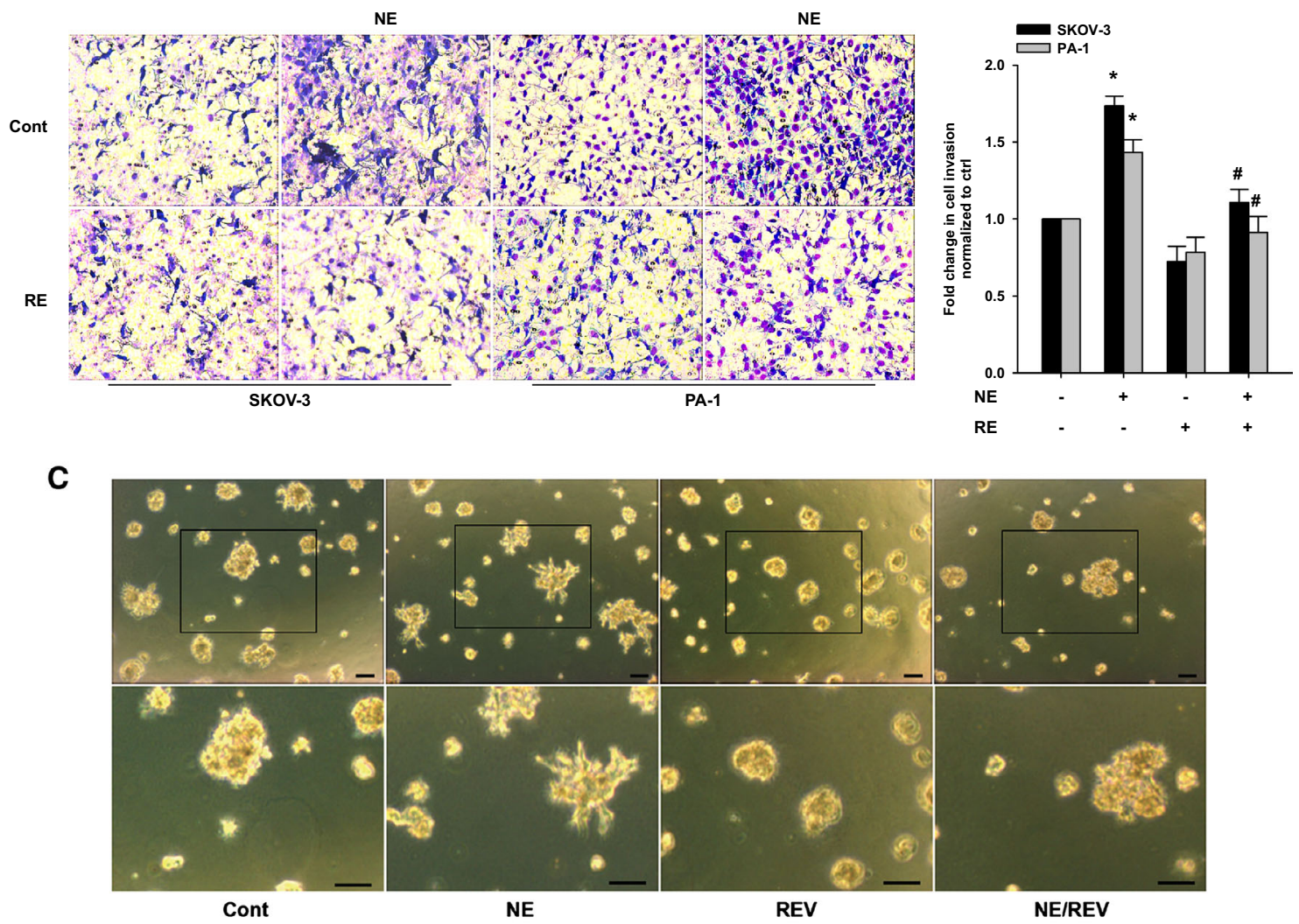

Fig. 1 REV inhibits NE-induced ovarian cancer cell invasion. a Cell viability assay was analyzed as MTT. The serum-starved cells were treated with REV for $24 \mathrm{~h}$. b The serum-starved SKOV-3 and PA-1 cells were respectively pretreated with 25 and $10 \mu \mathrm{M}$ REV for $1 \mathrm{~h}$. Invasion assay against serum-free media with or without $10 \mu \mathrm{M} \mathrm{NE}\left({ }^{*} P<0.05\right.$ vs. vehicle-treated control, ${ }^{\#} P<0.05$ vs. NE treatment only). The vehicle of REV and NE were ethanol and $\mathrm{H}_{2} \mathrm{O}$, respectively and used as controls. c Invasive capacity measured using Matrigel 3D colony assay. The SKOV-3 cell line was grown in Matrigel for 10 days. Images original magnification $\mathbf{b} \times 200$ and $\mathbf{c} \times 100$; scale bar, $100 \mu \mathrm{m}$ 


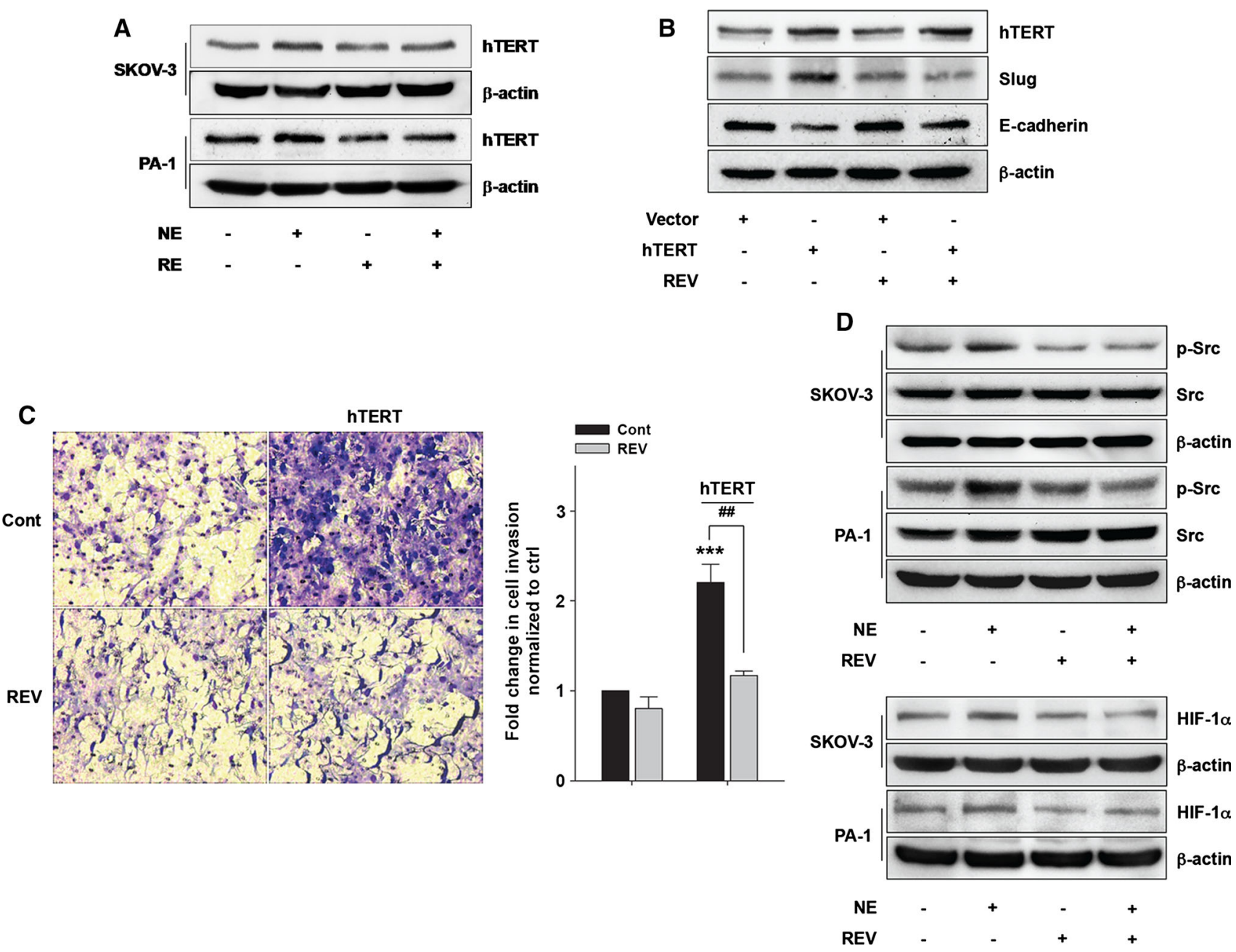

Fig. 3 REV inhibits NE-induced hTERT, Src, HIF-1 $\alpha$ expression. a The serum-starved SKOV-3 and PA-1 cells were respectively pretreated with 25 and $10 \mu \mathrm{M} \mathrm{REV}$ for $1 \mathrm{~h}$, followed by stimulation with $10 \mu \mathrm{M}$ NE for $24 \mathrm{~h}$. Lysates were collected and analyzed for hTERT by immunoblotting. b The cells were transfected with hTERT and serum-starved cells were treated with $25 \mu \mathrm{M}$ REV for $24 \mathrm{~h}$. Lysates were collected and analyzed for hTERT, Slug and E-cadherin by immunoblotting. $\mathbf{c}$ Invasion assay of transfected SKOV-3 cells with vector or hTERT against serum-free media with or without $25 \mu \mathrm{M}$ REV (***P $<0.001$ vs. vector and ${ }^{\# \#} P<0.01 \mathrm{vs.} \mathrm{hTERT} \mathrm{with} \mathrm{vehicle-treated} \mathrm{control).} \mathrm{d} \mathrm{The}$ serum-starved SKOV-3 and PA-1 cells were respectively pretreated with 25 and $10 \mu \mathrm{M}$ REV for $1 \mathrm{~h}$, followed by stimulation with $10 \mu \mathrm{M}$ NE for $24 \mathrm{~h}$ (upper) and $2 \mathrm{~h}$ (low). Lysates were collected and analyzed for hTERT, p-Src and HIF-1 $\alpha$ by immunoblotting 